\title{
Night Irrigation Reduction for Water Saving in Medium-Sized Systems
}

\author{
Bert De Bièvre ${ }^{1}$; Andrés Alvarado ${ }^{2}$; Luis Timbe ${ }^{3}$; Rolando Célleri' ${ }^{4}$; and Jan Feyen ${ }^{5}$
}

\begin{abstract}
In many medium-sized irrigation systems water is wasted during the night because demand is low and supply is not reduced accordingly. A hydrodynamic model was applied, using MIKE 11 as a software tool, to simulate abrupt discharge changes and their travel times along small irrigation canals. Filling and emptying of the canal were also analyzed. The model was calibrated with data of a field experiment that included startup, positive, and negative surges. A technique was developed to take into account the considerable water losses in the canal. Performance indicators efficiency, adequacy, equity, and dependability, proposed by Molden and Gates in 1990, were redefined using the concept of usefully delivered discharge. The newly defined indicators were consequently used to find the gate operation scenario that meets optimally the target day and night discharges. It was found that it is feasible to implement night delivery reduction. The calibrated model was used to develop guidelines for the operation of the canal with daily flow variation, resulting in considerable water savings during the night.
\end{abstract}

DOI: $10.1061 /(A S C E) 0733-9437(2003) 129: 2(108)$

CE Database subject headings: Hydraulic models; Irrigation practices; Hydraulic performance; Performance evaluation.

\section{Introduction}

Most canal irrigation water continues to flow at night, and much is poorly used or wasted (Chambers 1988). Yet, what happens to water at night, is a neglected subject. Darkness, cold, fear, and desire for sleep deter irrigation staff and farmers from activities at night.

Chambers (1988) suggests four measures to reduce irrigation at night with water saving. These all involve storage of water, that can be achieved in different ways: storage in main reservoirs, canals, intermediate storage reservoirs, on-farm reservoirs, and in groundwater. Of those, in the Andean case, storage in canals and in intermediate storage reservoirs cannot be applied because of the extremely difficult topography through which main canals are passing. Nor is groundwater storage an option in this mountainous environment. On-farm storage is applied but storage capacities are also limited by topography. The feasibility of the remaining option of storage in main reservoirs depends on the size of the irrigation system. On very large canals, regulation of head sluice

\footnotetext{
${ }^{1}$ Research Assistant, Laboratory for Soil and Water, Katholieke Univ. Leuven, Vital Decosterstraat 102, 3000 Leuven, Belgium. E-mail: bdebievr@ucuenca.edu.ec

${ }^{2}$ Research Assistant, Programa para el Manejo del Agua y del Suelo, Univ. of Cuenca, P.O. Box 168, Cuenca, Ecuador.

${ }^{3}$ Research Assistant, Programa para el Manejo del Agua y del Suelo, Univ. of Cuenca, P.O. Box 168, Cuenca, Ecuador.

${ }^{4}$ Research Assistant, Programa para el Manejo del Agua y del Suelo, Univ. of Cuenca, P.O. Box 168, Cuenca, Ecuador.

${ }^{5}$ Professor, Laboratory for Soil and Water, Katholieke Univ. Leuven, Vital Decosterstraat 102, 3000 Leuven, Belgium.

Note. Discussion open until September 1, 2003. Separate discussions must be submitted for individual papers. To extend the closing date by one month, a written request must be filed with the ASCE Managing Editor. The manuscript for this paper was submitted for review and possible publication on November 1, 2001; approved June 4, 2002. This paper is part of the Journal of Irrigation and Drainage Engineering, Vol. 129, No. 2, April 1, 2003. CASCE, ISSN 0733-9437/2003/2$108-116 / \$ 18.00$
}

openings from reservoirs to reduce deliveries at night is not feasible because of the long distances and traveling times involved (Chambers 1988). However, this study shows that there is an important class of intermediate size systems where daily regulation is feasible, resulting in considerable water savings.

In the Andes one can find many irrigation systems which typically irrigate a net area of a few hundred hectares and which have design discharges of less than $1 \mathrm{~m}^{3} / \mathrm{s}$. Main canals are typically 10 to $30 \mathrm{~km}$ long and conduct the water from some mountain river, whose flow may be regulated by one or several reservoirs upstream, to the spots of irrigated land. Those systems generally suffer from shortages in water supply, due to (1) extension of the irrigated area beyond the original design, under political pressure; (2) high-conveyance losses; and (3) poor management. Farmers usually irrigate during the day. Night irrigation is not only uncomfortable for the farmers but also technically difficult because of the adverse topography (with slopes up to 30\%).

In this study the hydrodynamic module (HD) of the MIKE 11 software package (Havnø et al. 1995) is used as a decision support tool in the definition and implementation of flow rate reduction during the night.

\section{Methods and Materials}

\section{Model Description}

MIKE $11 \mathrm{HD}$ uses an implicit, finite difference scheme to solve the Saint-Venant equations for the computation of unsteady flows in open channels (or rivers). The module can describe subcritical as well as supercritical flow conditions through a numerical scheme which adapts according to the local flow conditions (in time and space). The results of HD simulation consist of a time series of water levels and discharges. The modeling system is equipped with database systems and with graphical and digital 


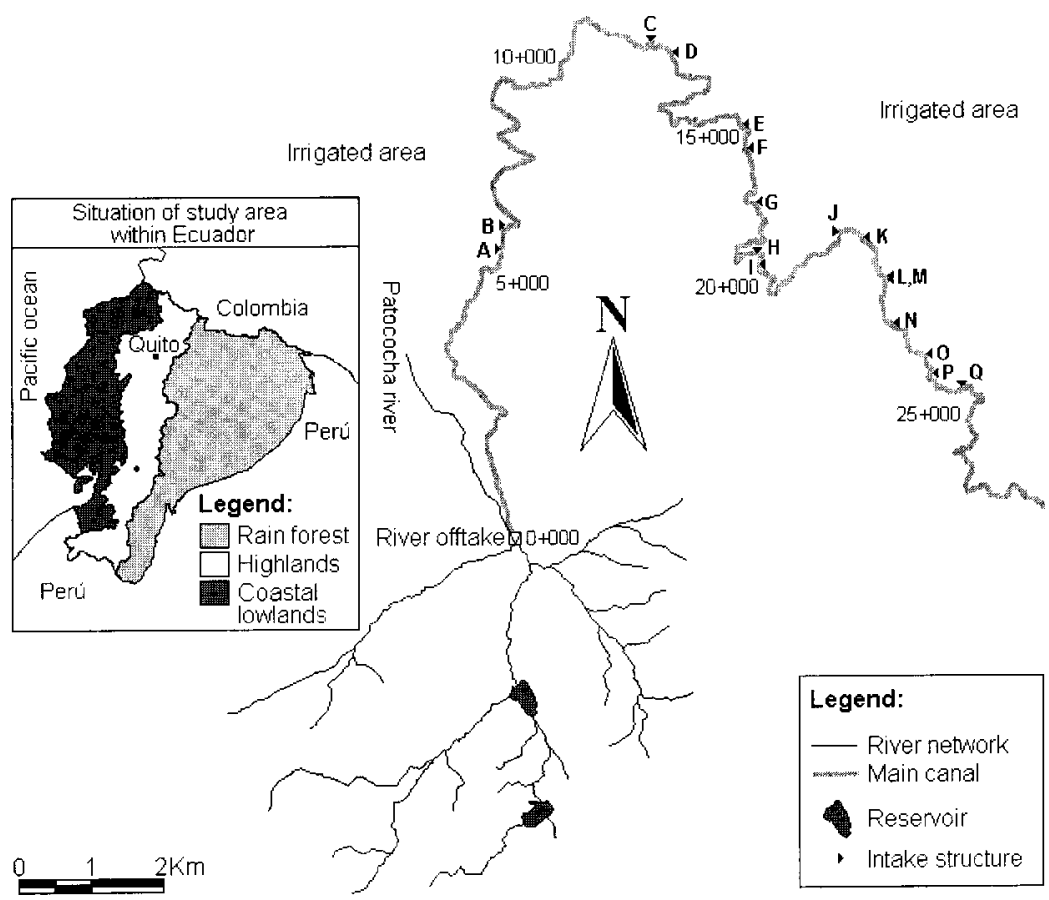

Fig. 1. Patococha irrigation scheme and its situation within Ecuador

pre- and post-processors for presenting input data and results. In this study, the SO structure operation module of the MIKE 11 software package was also used. The latter describes the flow over hydraulic structures and includes the possibility to describe operation of gates and regulators in canals. MIKE $11 \mathrm{HD}$ was already successfully used to improve the operation and management of irrigation canals through performance assessment (Mishra et al. 2001).

Because the modeling includes filling and emptying of the canal, special attention was paid to dry-bed flow. These flow conditions present certain difficulties with regard to mathematical simulation because of the existence of two-dimensional (nonhydrostatic) flow near the advancing or receding front and because of special computational-node requirements during the dry-bed flow (Holly and Merkley 1993). MIKE 11 handles low-flow conditions introducing a narrow slot below the cross section so that calculations can continue when the water surface falls below the bottom of the bed. If the water level reaches the bottom of the slot, a small amount of water is automatically added to prevent a complete drying out (Danish Hydraulic Institute 1997). The applied slot shape starts at a height $\Delta H$ above the river bottom and extends to $5^{*} \Delta H$ below.

\section{Patococha Irrigation Scheme}

The Patococha irrigation scheme (Fig. 1) consists of a river offtake at 3,400 $\mathrm{m}$ above sea level, in a small river descending from the "páramo" (highlands with low vegetation). Two upstream reservoirs, connected in series, in the river course were recently incorporated into the system. The reservoirs make storage of water which is saved by a canal flow rate reduction (for instance at night) possible. The lined main irrigation canal has a capacity of $0.5 \mathrm{~m}^{3} / \mathrm{s}$, a length of $25 \mathrm{~km}$ and a uniform longitudinal slope of 0.002 . Because of the steep slope of the land (100$200 \%$ ), the secondary distribution system was designed with PVC pipes. The 17 intake structures of the secondary pipe system consist of a S-shaped broad-crested weir in the main canal and a lateral gate upstream. The secondary intakes, numbered from A to $\mathrm{Q}$ have very variable capacities. Other features of the main canal include 27 discharge measuring structures in the form of broadcrested weirs, implemented for monitoring and mitigating canal seepage losses.

The total irrigable area is 1,100 ha within a gross area of 10,000 ha. This project was selected as being representative for the formerly state-owned, irrigation schemes in the high mountains of the Andes.

During the dry season, irrigation is generally deficient. Minimum discharges as low as $0.1 \mathrm{~m}^{3} / \mathrm{s}$ have been registered, so there is an urgent need for operating procedures to be optimized.

\section{Model Setup}

In an extensive field measurement campaign, cross sections, layout, hydraulic structure parameters, and canal roughness were measured (Bojorque et al. 1997). A total of 114 canal cross sections were entered into the model of which 82 are immediately upstream and downstream of the weirs. The water loss module of MIKE 11 could not be used to quantify the canal seepage losses, since water losses mainly occur via discrete points along the lined canal system, and also because in those points losses are proportional to the discharge rate. Therefore, losses were simulated through the inclusion of fictitious side canals through which the losses are evacuated from the main canal. The losses are specified by (1) the bottom level of the fictitious canal which may be higher than the bottom level of the main canal (this would simulate a loss to occur only from a threshold discharge on), and (2) a structure with a $Q_{\text {lost }} / Q_{\text {main channel }}$ relationship.

In preliminary model runs, maximum space and time steps that do not affect the accuracy of the results were determined in order to use minimum computation time for subsequent simulations. The values were found to be the combination time step/space step equal to 5 seconds/80 meter. 


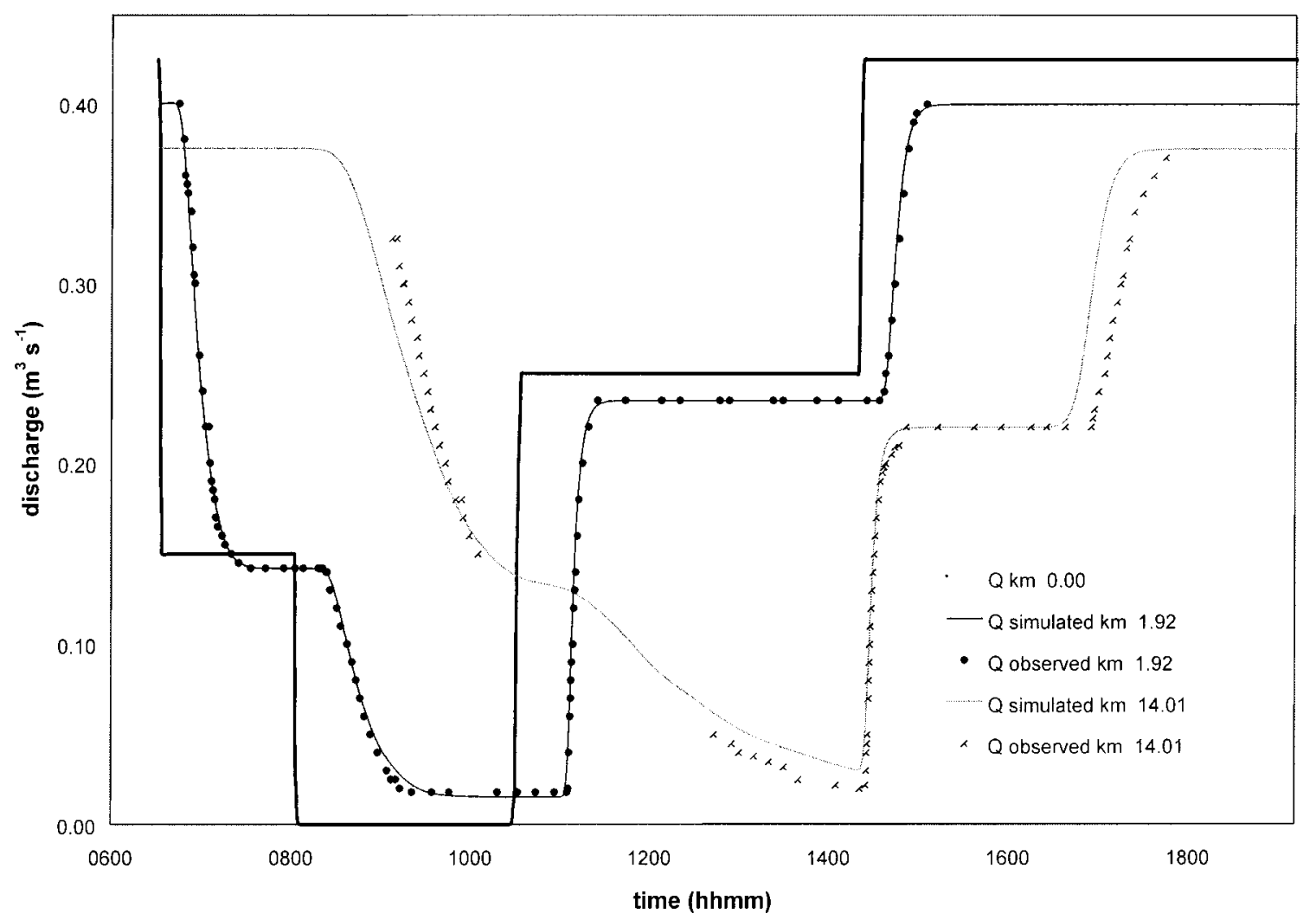

Fig. 2. Measured flow rates in advance and recession field experiments as compared to simulated values after calibration

\section{Model Calibration and Validation}

Calibration of hydraulic models is needed if the model is used for the operation of an existing system (Contractor and Schuurmans 1993). The most apparent calibration parameters are the canalroughness coefficients, the canal leakage losses, and the discharge coefficient of structures. These parameters were first determined by field measurements under steady-state conditions and then adjusted in the calibration process in order to have the best match between model results and real discharge data measured. Discharge measurements for calibration were done during an experiment in which discharge at the headworks was varied abruptly from an initial 0.425 to $0.15 \mathrm{~m}^{3} / \mathrm{s}$ (a recession jump or negative surge), later to 0 (emptying of the canal), subsequently to 0.25 $\mathrm{m}^{3} / \mathrm{s}$ (filling of the canal), and finally back to $0.425 \mathrm{~m}^{3} / \mathrm{s}$ (an advance jump or positive surge). The experiment allowed at first instance to calibrate the canal seepage losses, since after each surge steady-state conditions were reached and discharge could be determined along the canal for headworks discharges of 0.15 , 0.25 , and $0.425 \mathrm{~m}^{3} / \mathrm{s}$. This allowed us to determine the $Q_{\text {lost }} / Q_{\text {main channel }}$ relationship of the fictitious side canals, representing the canal seepage losses. In a next step, canal roughness coefficients were calibrated, since the model was found to be much more sensitive to roughness coefficients than to the discharge coefficients of the weirs. Calibrated values tended to be slightly higher than measured ones. The average calibrated Manning roughness of the canal was found to be 0.021 . Calibration was "fine-tuned" with the discharge coefficients of the broadcrested weirs. A full description of this process is given by Alvarado (2001).

Fig. 2 presents the measured and simulated flow rate after model calibration. As can be observed in the figure, the experiment includes filling and emptying of the canal, at least in the first stretch. Downstream, $0.205 \mathrm{~km}$, the canal was never dry because there was a lateral inflow at this point. Although dry-bed flow is a tough condition for a model to manage (Holly and Merkley 1993), measured advance and recession during filling and emptying match rather well.

Goodness-of-fit was evaluated with four parameters proposed by Lettenmaier and Wood (1993) and by Legates and McCabe (1999): the coefficient of determination or Nash-Sutcliffe coefficient $\mathrm{CD}$, the correlation coefficient $R^{2}$, the root-mean-square Error RMSE, and absolute error ABSERR.

All statistic parameters' values were satisfactory for all locations, however there is some deterioration in the values at further downstream points. Results are summarized in Table 1.

Model validation was done with data from a second experiment, which included startup from 0 to $0.25 \mathrm{~m}^{3} / \mathrm{s}$, a positive surge from 0.25 to $0.4 \mathrm{~m}^{3} / \mathrm{s}$, and a negative surge from 0.4 to $0.2 \mathrm{~m}^{3} / \mathrm{s}$. Goodness-of-fit measures are given in Table 2. It should be mentioned that a time lap between observed and simulated surge is considered as an extreme error by CD, RMSB, and ABSERR, since differences between observed and simulated discharge is very high during this period. This is why values for these parameters are of less quality than those for the calibration experiment.

\section{Performance Assessment}

Numerous definitions dealing with the evaluation of irrigation water use exist. Many of those are not essentially different from each other. Their use should be tuned to the circumstances of the irrigation system as well as to the purpose of the evaluation (Sanaee Jahromi and Feyen 2001).

Molden and Gates (1990) present a set of performance measures for the evaluation of irrigation-water-delivery systems: ad- 
Table 1. Statistical Parameters at Various Locations for Calibration Experiment

\begin{tabular}{lcccc}
\hline $\begin{array}{l}\text { Distance from } \\
\text { beginning of } \\
\text { canal }(\mathrm{m})\end{array}$ & $\mathrm{CD}$ & $R^{2}$ & $\begin{array}{c}\text { RMSE } \\
\left(\mathrm{m}^{3} \mathrm{~s}^{-1}\right)\end{array}$ & $\begin{array}{c}\text { ABSERR } \\
\left(\mathrm{m}^{3} \mathrm{~s}^{-1}\right)\end{array}$ \\
\cline { 2 - 5 } 1,998 & $\cdots$ & $\cdots$ & 0.0093 & 0.0061 \\
5,769 & 0.993 & 0.994 & 0.0096 & 0.0069 \\
7,923 & 0.992 & 0.993 & 0.0211 & 0.0174 \\
10,102 & 0.959 & 0.965 & 0.0271 & 0.0190 \\
12,264 & 0.926 & 0.940 & 0.0282 & 0.0184 \\
14,093 & 0.908 & 0.943 & 0.028 & 0.0245 \\
\hline
\end{tabular}

equacy, efficiency, dependability, and equity of water delivery. The indicators provide a quantitative assessment of the overall system performance and of the contributions of structural and management components of the system to performance. In design of scheduling, as is the case in this study, the performance evaluation is limited to the structural (hydraulic) component, since the search is for the optimal scenario of the operation of the studied system, assuming that implementation of this schedule later will be adequate.

Efficiency is a measure for how much water is being supplied and not used, thus lost. No losses result in a value of unity. Adequacy is a measure of how well the demand is met and is equal to unity if all water requirements are fulfilled. Dependability is the degree of temporal variability of the deviations of delivered water from the target value and is ideally zero. Equity is the degree of spatial variability of the deviations of delivered water from the target and is also equal to zero in ideal cases.

For quantification of these performance indicators, the state variables have to be defined. They can be defined in terms of discharge rates. Since we are in a design or optimization phase, scheduled discharge $Q_{s}$ can be assumed equal to the required discharge. Deliverable discharge $Q_{d}$ is the one that could be delivered by the system with perfect operation and is obtained after optimization through the simulation model. Usefully delivered water $Q_{u}$ is defined as

$$
\begin{aligned}
& Q_{u}=Q_{d} \text { when } Q_{d}<Q_{s} \\
& Q_{u}=Q_{s} \text { when } Q_{s}<Q_{d}
\end{aligned}
$$

It corresponds to water that was delivered within the requirements, excluding both water that was delivered but not required and water that was required but not delivered.
Table 2. Statistical Parameters at Various Locations for Validation

\begin{tabular}{|c|c|c|c|c|}
\hline \multirow{2}{*}{$\begin{array}{l}\text { Distance from } \\
\text { beginning of } \\
\text { canal }(\mathrm{m})\end{array}$} & \multicolumn{4}{|c|}{ Statistical Parameters } \\
\hline & $\begin{array}{l}\mathrm{CD} \\
\cdots\end{array}$ & $\begin{array}{l}R^{2} \\
\cdots\end{array}$ & $\begin{array}{c}\text { RMSE } \\
\left(\mathrm{m}^{3} \mathrm{~s}^{-1}\right)\end{array}$ & $\begin{array}{c}\text { ABSERR } \\
\left(\mathrm{m}^{3} \mathrm{~s}^{-1}\right)\end{array}$ \\
\hline 414 & 0.729 & 0.934 & 0.0503 & 0.0364 \\
\hline 1,414 & 0.409 & 0.856 & 0.0733 & 0.0472 \\
\hline 2,478 & 0.381 & 0.863 & 0.0756 & 0.0537 \\
\hline 4,910 & 0.436 & 0.839 & 0.0663 & 0.0471 \\
\hline
\end{tabular}
Experiment

The concepts are clarified by means of the graphs in Fig. 3. In this example, a demand $Q_{s}$ of $Q_{1}$ exists during the night and a higher demand $Q_{2}$ during the day. Three scenarios for deliverable water $Q_{d}$ are presented. The situation of graph (a) results in an efficiency of $100 \%$ (no losses) and a low adequacy. The pattern in graph (b) results in a low efficiency (high losses) but an adequacy of $100 \%$ (all demand is met). Graph (c) presents an intermediate situation with both efficiency and adequacy less than $100 \%$.

Since delivery cannot be abruptly changed because of canal hydraulics, it will never be possible to obtain an efficiency and adequacy of both $100 \%$ for this demand pattern. An optimal scenario has to be found in which both indicators are weighted. If water is very scarce, it will be appropriate to give a higher importance to efficiency than adequacy. On the contrary, in case consequences of nondelivery of water are severe, it will be appropriate to give a higher importance to adequacy.

In this study, the performance measures of Molden and Gates (1990) are reformulated in terms of integrals of the discharge functions, and the concept of usefully delivered discharge $Q_{u}$ is included.

The equation for efficiency $e$ at any point $i$ at any time then is

$$
e=\frac{Q_{u i}}{Q_{d i}}
$$

And its temporal average $E_{i}$ at point $i$

$$
E_{i}=\frac{\int Q_{u i} d t}{\int Q_{d i} d t}
$$

Adequacy $a$ at any point $i$ at any time is

$$
a=\frac{Q_{u i}}{Q_{s i}}
$$

And its temporal average $A_{i}$ at point $i$

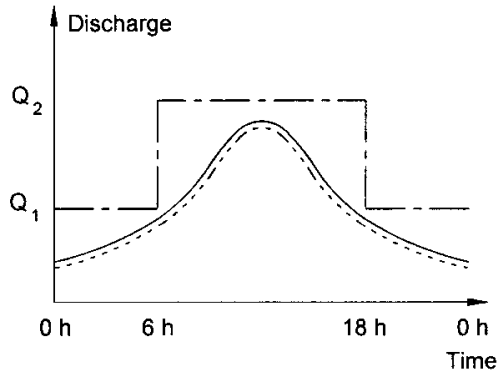

(a)

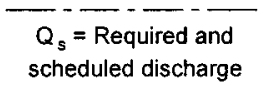

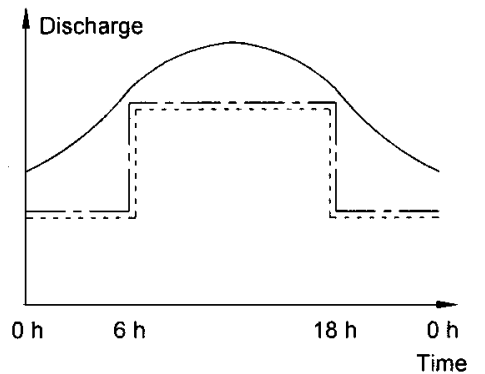

(b)

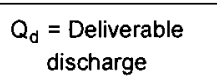

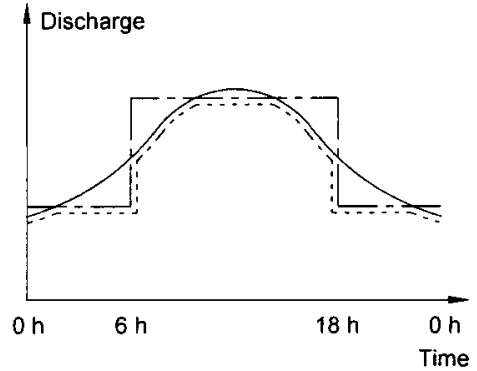

(c)

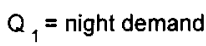

$Q_{2}=$ day demand

Fig. 3. Water demand pattern and different delivery patterns 
Table 3. Overview of Performance Indicators

Reach over Which Performance is Evaluated

\begin{tabular}{|c|c|c|c|c|}
\hline Indicator & $\begin{array}{l}\text { At specific } \\
\text { point and } \\
\text { time }\end{array}$ & $\begin{array}{c}\text { Temporal average } \\
\text { at any point }\end{array}$ & $\begin{array}{c}\text { Spatial average at } \\
\text { any time }\end{array}$ & $\begin{array}{c}\text { Global (temporal and spatial } \\
\text { average) }\end{array}$ \\
\hline Efficiency & $e=\frac{Q_{u i}}{Q_{d i}}$ & $E_{i}=\frac{\int Q_{u i} d t}{\int Q_{d i} d t}$ & $E_{t}=\frac{\sum_{i} Q_{u i}}{\sum_{i} Q_{d i}}$ & $E_{G}=\frac{\sum_{i} \int Q_{u i} d t}{\sum_{i} \int Q_{d i} d t}$ \\
\hline Adequacy & $a=\frac{Q_{u i}}{Q_{s i}}$ & $A_{i}=\frac{\int Q_{u i} d t}{\int Q_{s i} d t}$ & $A_{t}=\frac{\sum_{i} Q_{u i}}{\sum_{i} Q_{s i}}$ & $A_{G}=\frac{\sum_{i} \int Q_{u i} d t}{\sum_{i} \int Q_{s i} d t}$ \\
\hline Dependability & - & $D_{i}=\mathrm{CV}_{T}\left(\frac{Q_{d i}}{Q_{s i}}\right)$ & - & $D_{G}=\frac{1}{Q_{D}} \sum_{i} Q_{D i} \mathrm{CV}_{T}\left(\frac{Q_{d i}}{Q_{s i}}\right)$ \\
\hline Equity & - & - & $\mathrm{Eq}_{t}=\mathrm{CV}_{R}\left(\frac{Q_{d}}{Q_{s}}\right)$ & $\mathrm{Eq}_{G}=\frac{1}{T} \int \mathrm{CV}_{R}\left(\frac{Q_{d}}{Q_{s}}\right) d t$ \\
\hline
\end{tabular}

$$
A_{i}=\frac{\int Q_{u i} d t}{\int Q_{s i} d t}
$$

In this way, efficiency and adequacy can be calculated at every point where a demand exists, basically at the secondary outlets of the main canal. Global efficiency of the system can then be defined as the total usefully delivered water divided by the total delivered water, and global adequacy as the total usefully delivered water divided by total demand

$$
\begin{aligned}
E_{G} & =\frac{\sum_{i} \int Q_{u i} d t}{\sum_{i} \int Q_{d i} d t} \\
A_{G} & =\frac{\sum_{i} \int Q_{u i} d t}{\sum_{i} \int Q_{s i} d t}
\end{aligned}
$$

in which the summation is over all canal outlets.

In their work, Molden and Gates define two additional performance indicators: dependability and equity of water delivery. These indicators are also adapted for use in this study. Dependability is a measure for "consistency" in the operation of the system. It is defined as the temporal variability of the ratio of the delivered amount of water to the scheduled amount, i.e., at a point $i$

$$
D_{i}=\mathrm{CV}_{T}\left(\frac{Q_{d i}}{Q_{s i}}\right)
$$

where $\mathrm{CV}_{T}\left(Q_{d i} / Q_{s i}\right)$ is the temporal coefficient of variation (ratio of standard deviation to mean) of the ratio (delivered discharge at outlet $i$ /scheduled discharge at outlet $i$ ) over the time period $T$ (1 day). Global dependability can be obtained as a weighted average of dependabilities at the different outlets.

$$
\begin{gathered}
D_{G}=\frac{1}{Q_{D}} \sum Q_{D i} \mathrm{CV}_{T}\left(\frac{Q_{d i}}{Q_{s i}}\right) \\
Q_{D}=\sum_{i} Q_{D i}
\end{gathered}
$$

where $Q_{D i}$ is the design discharge of outlet $i$.

Equity evaluates if all users (outlets) receive a fair share of the water and can be defined at any time as

$$
\mathrm{Eq}_{t}=\mathrm{CV}_{R}\left(\frac{Q_{d}}{Q_{s}}\right)
$$

where $\mathrm{CV}_{R}\left(Q_{d} / Q_{s}\right)=$ spatial coefficient of variation of the ratio $Q_{d} / Q_{s}$ over the different canal outlets. Global equity would then be

$$
\mathrm{Eq}_{G}=\frac{1}{T} \int \operatorname{CV}_{R}\left(\frac{Q_{d}}{Q_{s}}\right) d t
$$

Table 3 gives a summary of the proposed performance indicators at different levels of evaluation. Additionally to the abovementioned ones, it includes spatially averaged efficiency and adequacy at any time.

\section{Results and Discussion}

\section{Travel Times}

In order to give system operators the necessary information to implement a reduced night discharge schedule, at first instance travel times of surges in the canal were calculated. This was done for positive surges (advance) and negative surges (recession) and for a total of 210 combinations of initial and target discharge. Travel times were determined for the surge to reach different points along the canal, i.e., the time until the steady-state condition is reached. Additionally, times needed to complete only $90 \%$ of the surge were calculated, since this gives an idea when the target discharge is almost reached and time to complete $100 \%$ of the surge can be considerably longer. This is especially the case for emptying of the canal or recession to a small discharge. Fig. 4 presents travel times in hours from the river offtake to $15.906 \mathrm{~km}$ of the canal. Graphs (a) and (b) give travel times in hours, when all lateral gates down to this point are closed, graphs (c) and (d) are with open gates. Graphs (a) and (c) give the travel times to reach $90 \%$ of the target discharge and graphs (b) and (d) the times to complete $100 \%$ of the surge.

Travel times for the open gates situation are quite similar to the ones for the closed gates situation, but the difference becomes considerable for emptying of the canal. Travel times in hours, for completion of the target are about $20 \%$ higher than for completion of $90 \%$ of the target, except for emptying or near emptying when the difference gets much wider. Although those graphs are not symmetrical - negative surges have a longer travel time than positive ones between the same discharges - continuity exists across 


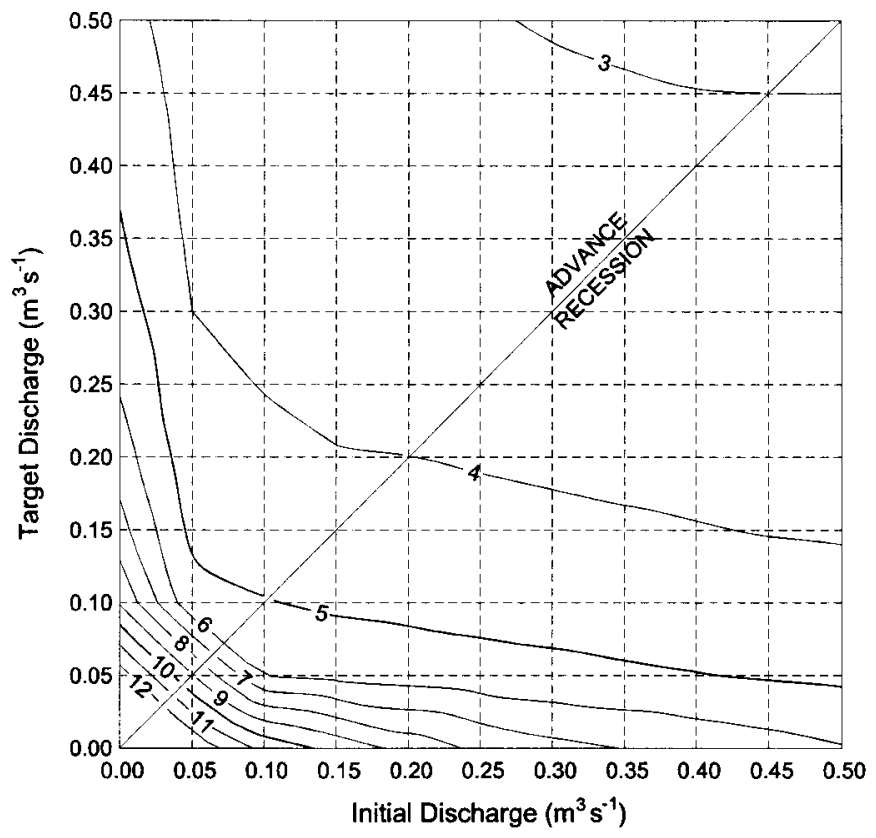

(a)

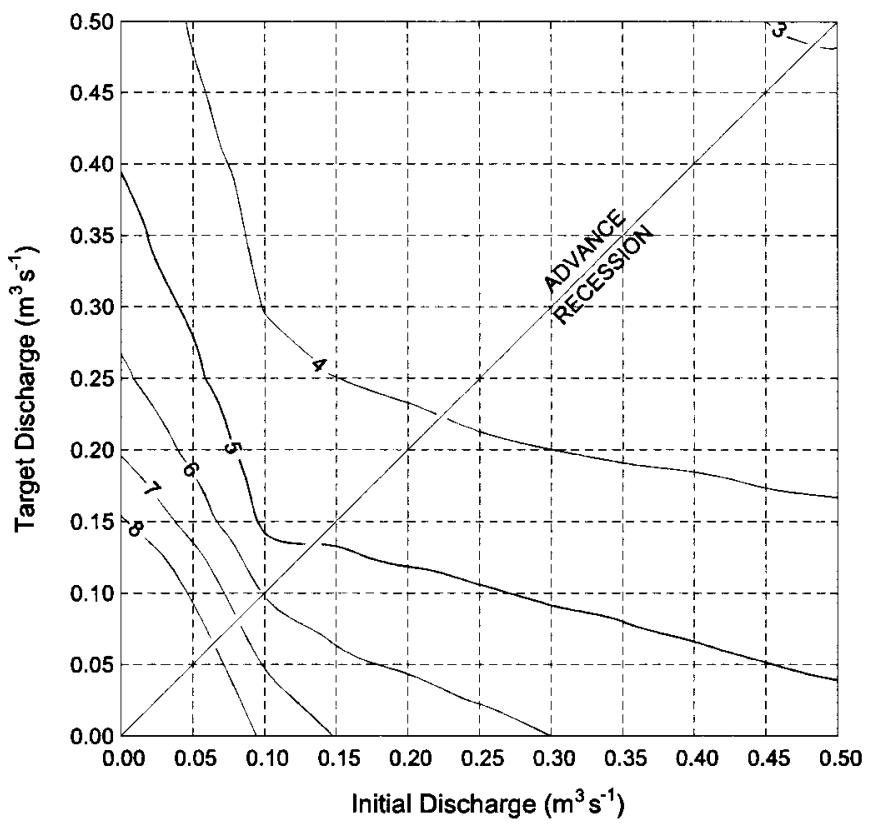

(c)

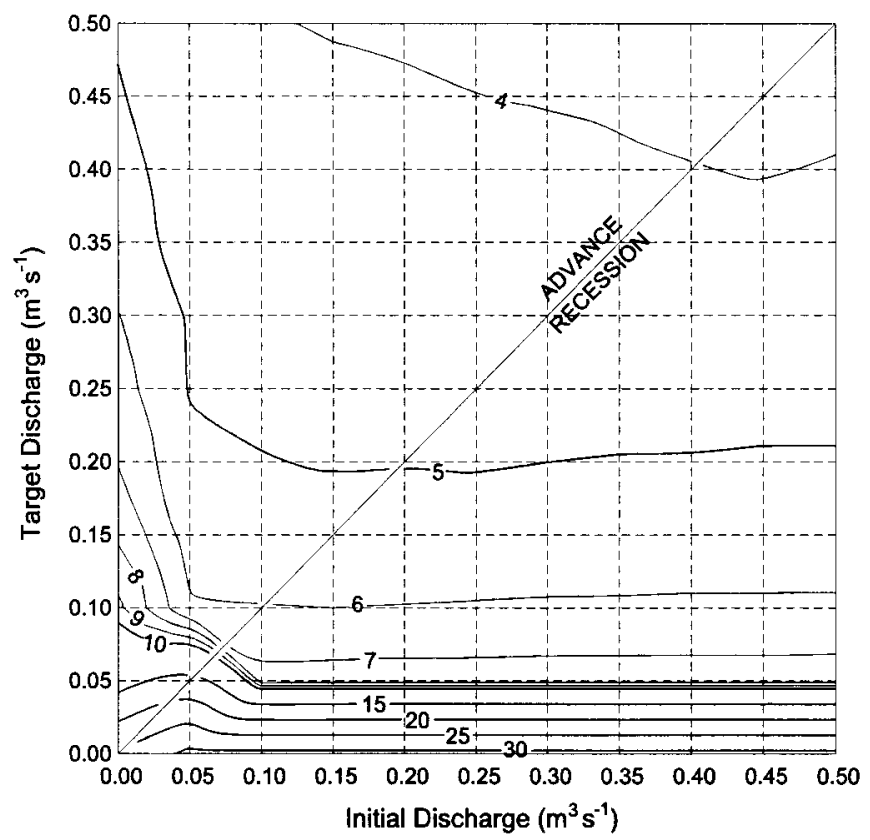

(b)

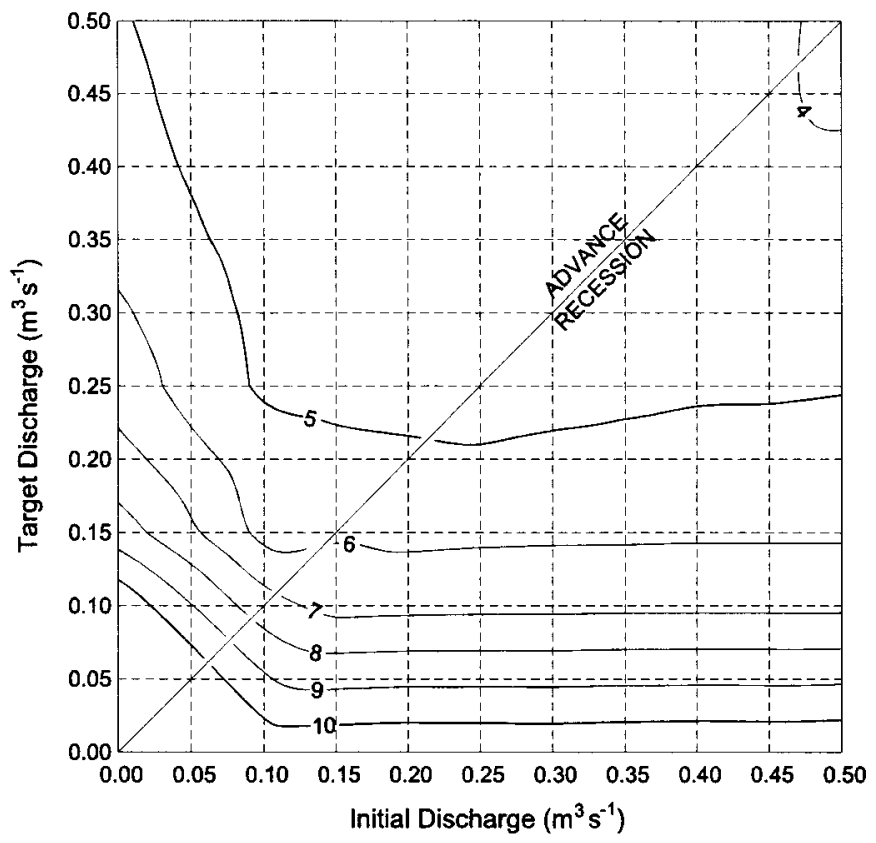

(d)

Fig. 4. Travel times of surges to reach $15.906 \mathrm{~km}$ of canal

the bisectrix line which represents no surge, i.e., a small positive surge and a negative one of the same magnitude have the same travel time.

\section{Performance Indicators for Different Scenarios}

As an example, the following scenario is presented: The outlets A to $\mathrm{L}$, which have a total design discharge of $0.24 \mathrm{~m}^{3} / \mathrm{s}$ (individual outlets have highly variable design discharges between 0.01 and $0.1 \mathrm{~m}^{3} / \mathrm{s}$ ) are in use and the other outlets are closed. The demand pattern was supposed to be $0.28 \mathrm{~m}^{3} / \mathrm{s}\left(0.24 \mathrm{~m}^{3} / \mathrm{s}+\right.$ canal seepage losses) during the day (from 0600 to $1800 \mathrm{hrs}$ ) and $0.14 \mathrm{~m}^{3} / \mathrm{s}$ during the night. Gate keepers are supposed to open the outlet gates completely at $0600 \mathrm{hrs}$ and close them at $1800 \mathrm{hrs}$ to such an extent that half of the design discharge of the outlet is passing. This is an idealized situation but valid to determine optimal headworks gate operation.

In different runs, opening time of the headworks gate was varied between midnight and $0400 \mathrm{hrs}$ and closing time between noon and $1600 \mathrm{hrs}$. Global performance indicators were calculated for a grid size of half an hour and interpolated. The result is given in Fig. 5. It can be seen that efficiency and adequacy are contradictory objectives. With the above-mentioned criteria of relative importance of efficiency and adequacy one can select an optimal scenario with the help of those graphs. For example, opening of the headworks gate at $0200 \mathrm{hrs}$ and closing at $1330 \mathrm{hrs}$ 


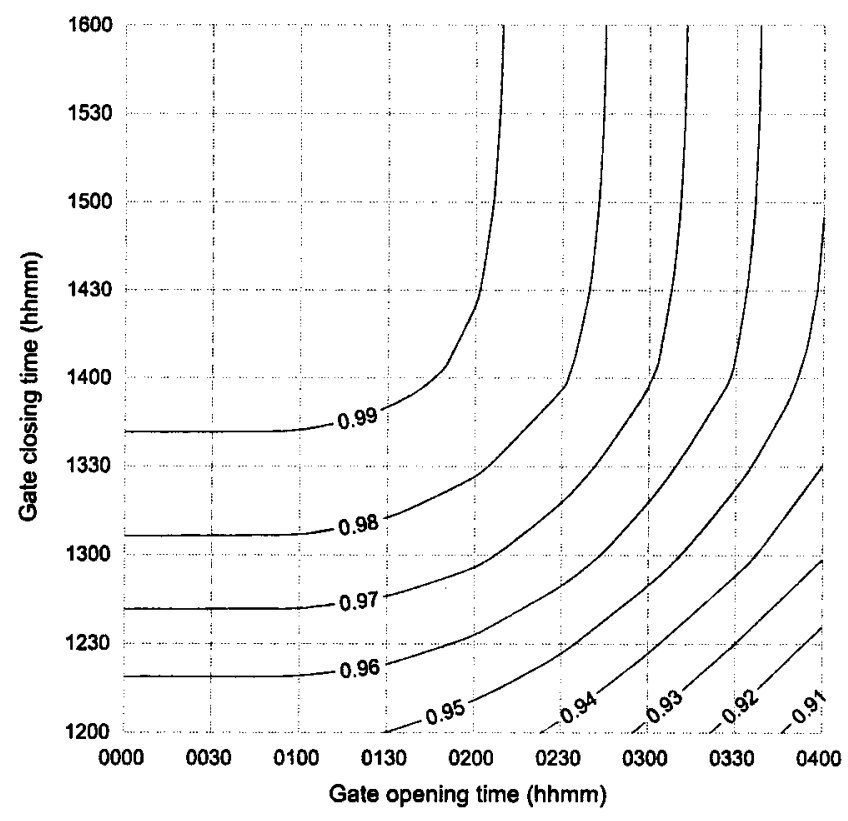

(a) Adequacy

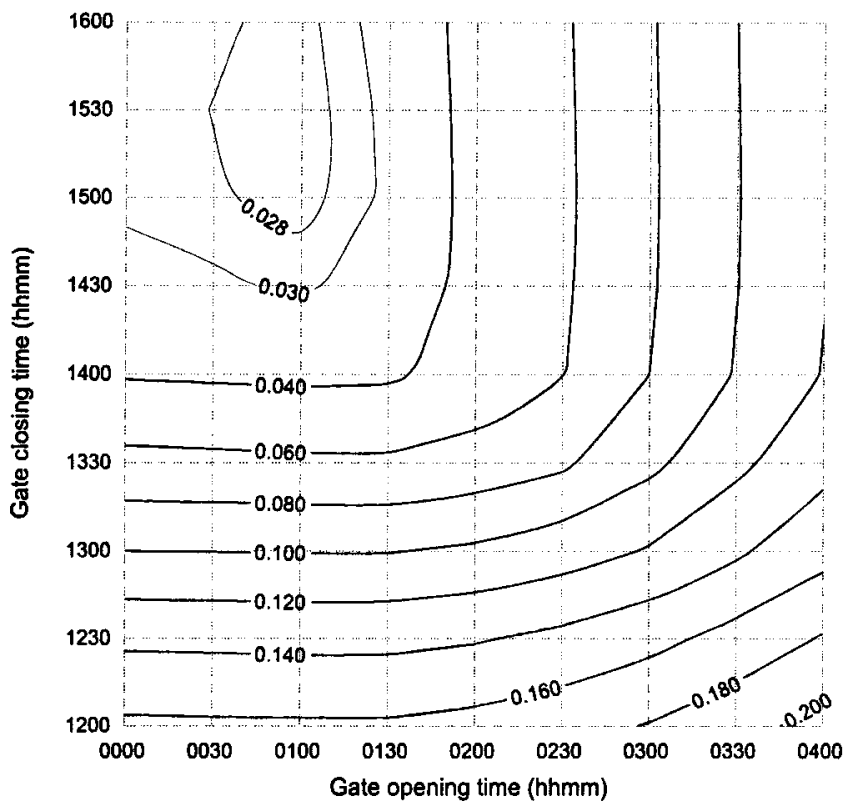

(c) Dependability

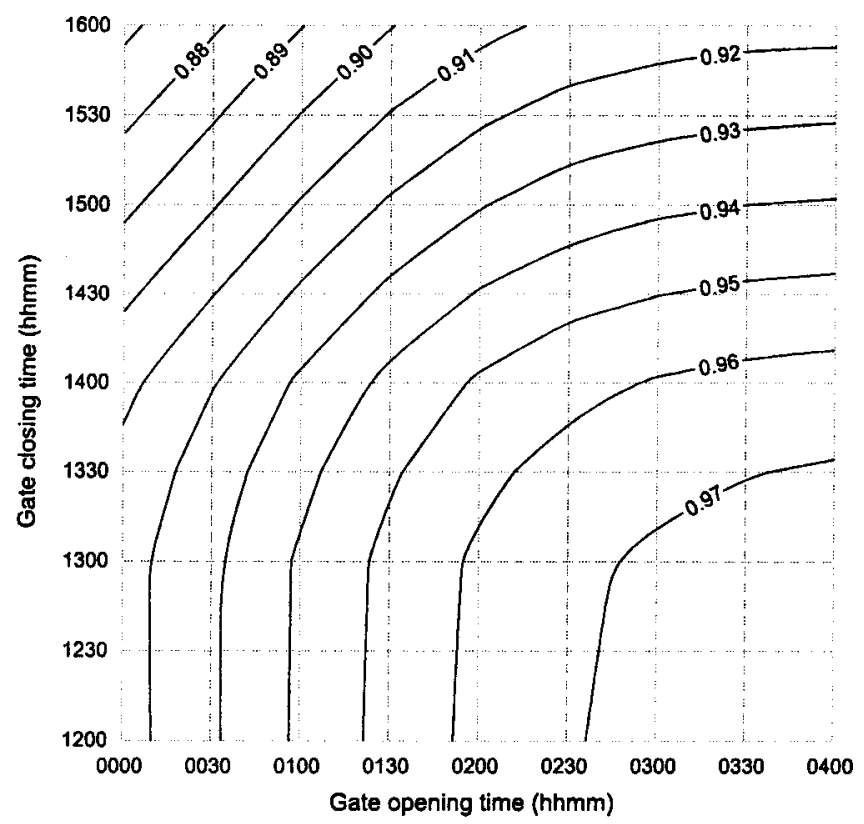

(b) Efficiency

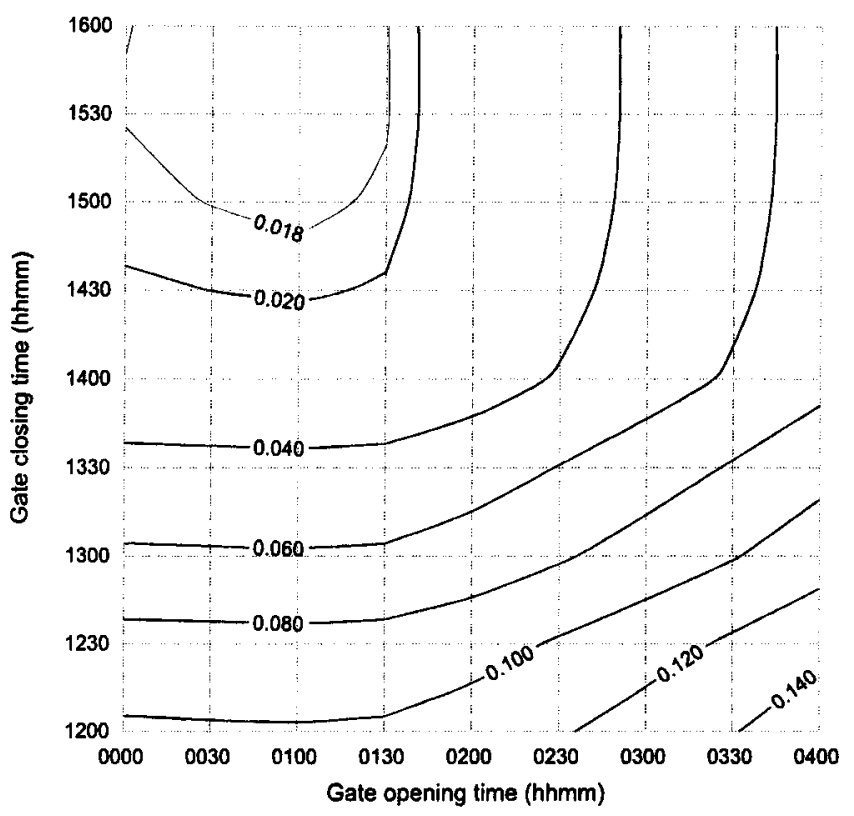

(d) Equity

Fig. 5. Performance indicators in function of gate opening and closing time for day and night demand of 0.28 and $0.14 \mathrm{~m}^{3} / \mathrm{s}$, respectively, and lateral gates' opening reduction at night

gives reasonable values of $98 \%$ for adequacy, $96 \%$ for efficiency, 0.05 for equity, and 0.07 for dependability. It is to be mentioned that in this case the reference scenario of no night discharge reduction has an adequacy of $100 \%$ and an efficiency of $75 \%$.

Another scenario is analyzed in order to see if it is feasible to avoid the daily closing and opening of the lateral gates. If night discharge is not zero, and lateral gate openings are not reduced at night, all the water will be delivered to the upper outlets and no water to the lower outlets, resulting in very poor values of the indicators. However, if the night discharge is zero, reasonable performance indicators can be obtained without daily closing of lateral gates. Fig. 6 gives efficiency and adequacy for this situa- tion, with a day demand of $0.28 \mathrm{~m}^{3} / \mathrm{s}$, in function of the headworks gate opening and closing time. For this case, the reference scenario of no night discharge reduction has an adequacy of $100 \%$ and an efficiency of 50\%. Opening of the gate at $2200 \mathrm{hrs}$ and closing at 1300 hrs lowers adequacy to $91 \%$ but improves efficiency to $82 \%$.

\section{Conclusions}

The study shows that considerable water amounts are saved by reducing discharge rates in this type of canal at night. A hydraulic 


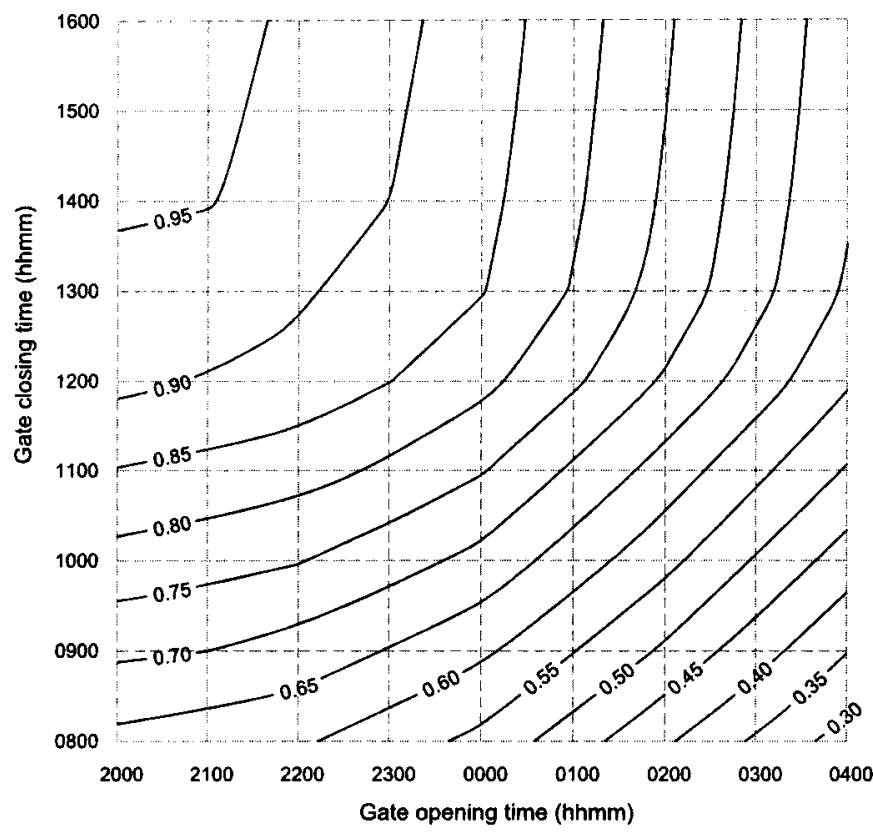

(a) Adequacy

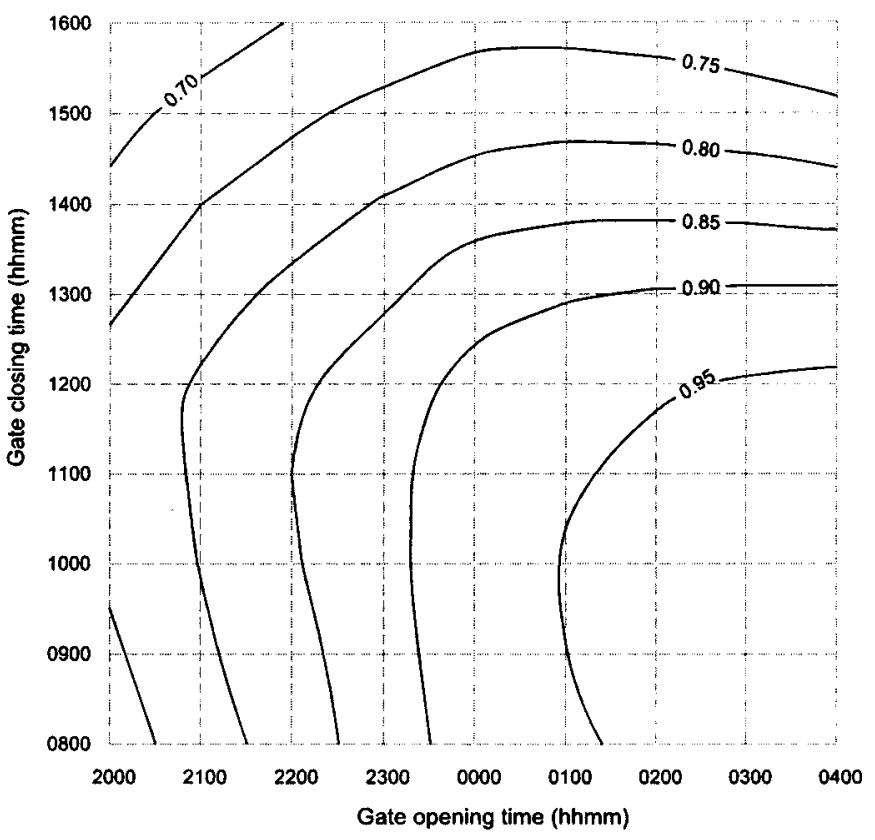

(b) Efficiency

Fig. 6. Adequacy and efficiency for day and night demand of 0.28 and $0 \mathrm{~m}^{3} / \mathrm{s}$, respectively, and without lateral gates' closure at night

model showed that night delivery reduction is feasible in terms of necessary operation procedures and order of magnitude of travel times involved. The model also provided guidelines for reducing discharge rates in order to obtain optimal performance. It was shown that a scenario in which the lateral intake gates are not operated can still yield good performance in case discharge is reduced to zero at night.

The presented charts are examples of tools that can be used by irrigation managers to implement a delivery schedule that includes daily flow variation.

\section{Acknowledgments}

This research was supported by the Flemish Interuniversity Council VLIR with Belgian government development cooperation funding and by the Ecuadorian Foundation for Science and Technology FUNDACYT through Grant No. P-BID-130.

\section{Notation}

The following symbols are used in this paper:

$A_{i}=$ temporal average of adequacy at point $i$ (dimensionless);

$A_{G}=$ global adequacy (dimensionless);

$A_{t}=$ spatial average of adequacy at time (dimensionless);

$a=$ adequacy at point $i$ at any time (dimensionless);

$D_{i}=$ dependability at any point $i$ (dimensionless);

$D_{G}=$ global dependability (dimensionless);

$E_{G}=$ global efficiency (dimensionless);

$E_{i}=$ temporal average of efficiency at point $i$ (dimensionless);

$E_{t}=$ spatial average of efficiency at time $t$ (dimensionless);

$e=$ efficiency at point $i$ at any time (dimensionless);
$Q_{D}=$ sum of design discharges of all canal outlets $\left(\mathrm{m}^{3} / \mathrm{s}\right)$;

$Q_{D i}=$ design discharge at outlet $i\left(\mathrm{~m}^{3} / \mathrm{s}\right)$;

$Q_{d}=$ deliverable discharge $\left(\mathrm{m}^{3} / \mathrm{s}\right)$;

$Q_{d i}=$ deliverable discharge at outlet $i\left(\mathrm{~m}^{3} / \mathrm{s}\right)$;

$Q_{s i}=$ scheduled discharge at outlet $i\left(\mathrm{~m}^{3} / \mathrm{s}\right)$;

$Q_{s}=$ scheduled required discharge $\left(\mathrm{m}^{3} / \mathrm{s}\right)$;

$Q_{u}=$ usefully delivered water $\left(\mathrm{m}^{3} / \mathrm{s}\right)$;

$Q_{u i}=$ usefully delivered demand at outlet $i\left(\mathrm{~m}^{3} / \mathrm{s}\right)$; and

$R^{2}=$ correlation coefficient (dimensionless).

\section{References}

Alvarado, A. (2001). "Modelización hidrodinámica de canales de riego medianos." Graduate thesis, Faculty of Engineering, Univ. de Cuenca, Cuenca, Ecuador (in Spanish).

Bojorque, J., Célleri, R., Idrovo, J., and Torres, P. (1997). "Medición y evaluación de parámetros hidráulicos para sistemas de riego." Graduate thesis, Faculty of Engineering, Univ. de Cuenca, Cuenca, Ecuador (in Spanish).

Chambers, R. (1988). "Canal Irrigation at Night." Managing canal irrigation, Cambridge University, Cambridge, England, 133-157.

Contractor, D. N., and Schuurmans, W. (1993). "Informed use and potential pitfalls of canal models." J. Irrig. Drain. Eng., 119(4), 663672.

Danish Hydraulic Institute (1997). "MIKE 11: A microcomputer based modeling system for rivers and channels; reference manual." Copenhagen, Denmark.

Havnø, K., Madsen, M. N., and J. Dørge, J. (1995). "MIKE 11-A generalized river modelling package." Computer models of watershed hydrology, V. P. Singh, ed., Water Resources Publications, Littleton, Colo., 733-782.

Holly, F. M., and Merkley, G. P. (1993). "Unique problems in modeling irrigation canals.” J. Irrig. Drain. Eng., 119(4), 656-662.

Legates, D., and McCabe, G. (1999). "Evaluating the use of "goodnessof-fit" measures in hydrologic and hydroclimatic model validation." Water Resour. Res., 35(1), 233-241. 
Lettenmaier, D., and Wood, E. (1993). "Hydrologic forecasting." Handbook of hydrology, D. R. Haidment, ed., McGraw-Hill, New York, 26.2-26.3.

Mishra, A., Anand, A., Singh, R., and Raghuwanshi, N. S. (2001). "Hydraulic modeling of Kangsabati main canal for performance assessment." J. Irrig. Drain. Eng., 127(1), 27-34.
Molden, D. J., and Gates, T. K. (1990). "Performance measures for evaluation of irrigation-water-delivery systems." J. Irrig. Drain. Eng., 116(6), 804-823.

Sanaee Jahromi, S., and Feyen, J. (2001). "Approach to the evaluation of undependable delivery of water in irrigation schemes." Irrig. Drain. Syst., 15, 197-213. 